\title{
Pesquisa sobre Inovação Tecnológica: o possível viés da informação em levantamentos
}

\author{
Maria do Carmo Romeiro \\ Universidade Municipal de São Caetano do Sul, São Caetano do Sul (SP), Brasil \\ Leandro Campi Prearo \\ Universidade Municipal de São Caetano do Sul, São Caetano do Sul (SP), Brasil \\ Marco Antonio Pinheiro da Silveira \\ Universidade Municipal de São Caetano do Sul, São Caetano do Sul (SP), Brasil \\ João de Paula Ribeiro Neto \\ Universidade Municipal de São Caetano do Sul, São Caetano do Sul (SP), Brasil
}

Recebido: 10/06/2011 Versão Revisada (entregue): 06/11/2012 Aprovado: 09/11/2012

\begin{abstract}
Resumo
Esse estudo aborda o viés da informação sobre a ocorrência de inovação em levantamentos, decorrente da compreensão imprecisa do conceito de inovação implícito na questão. $\mathrm{O}$ reconhecimento dessa situação ressalta a necessidade de procedimentos metodológicos que detectem o erro de compreensão do conceito por parte dos informantes, a fim que sejam previstos mecanismos para minimização do erro total da mensuração de indicadores de inovação. Um desenho desses procedimentos foi aplicado em levantamento amostral no setor metal mecânico da região do ABC. Nesse estudo foram cotejadas as respostas a questôes fechadas e abertas sobre a prática de inovação nas empresas. Dois fluxos metodológicos ilustram os procedimentos para detecção e correção do viés da informação, evidenciando a relevância do uso da questão aberta, na sequência da questão fechada sobre inovação. A diferença entre as
\end{abstract}


Maria do Carmo Romeiro, Leandro Campi Prearo, Marco Antonio Pinheiro da Silveira, João de Paula Ribeiro Neto

estimativas dos indicadores de inovação, obtidas com e sem a aplicação desses procedimentos, mostrou-se estatisticamente significante.

PALAVRas-Chave | Levantamento sobre Inovação Tecnológica; Viés; Questão Aberta; Instrumento de Coleta de Dados

Código JEL | O30

Technological Innovation Research: The Possible Information Bias in Surveys

ABSTRACT

This article shows the study about the bias of information in surveys about occurrence of innovation, due to inaccurate understanding of the concept of innovation implicit in the question. The recognition of this situation emphasizes the need for methodological procedures that detect the mistake of understanding of the concept by the informants in order to provide mechanisms to minimize the total error of measurement of innovation indicators. These procedures were applied to sample survey in Metal Mechanic Sector of the ABC Region, which were compared the responses to structured and unstructured questions about the practice of innovation in companies. Two flows show the methodological procedures for the detection and correction of information bias, which point out the use of unstructured question just after the structured question about innovation. The difference among the indicators innovation estimates - with and without the application of these procedures - was statistically significant.

KEYWORDS | Technological Innovation Surveys; Bias; Unstructured Question; Data Collection Instrument

JEL-CODE | O30 


\section{Introdução}

Esse estudo aborda o possível viés da informação declarada, por informantes em levantamentos, sobre a ocorrência de inovação. Esse viés é entendido como o desvio da compreensão do conceito de inovação pelo entrevistado em relação ao conceito de inovação implícito na pergunta, gerando erro nas estimativas dos indicadores relativos a inovação de produto e de processo.

A presença desse viés, ou erro sistemático como também é chamado, insere-se no escopo de erro não amostral, visto que é devido a fatores relacionados não ao processo de amostragem, mas sim a fontes ligadas ao processo de observação, mais precisamente a coleta do dado, na fonte respondente, impactando, assim, o erro total de levantamento (SMITH, 2011).

O esforço de busca de estudos envolvendo o viés, em decorrência do informante, nos levantamentos que objetivam estimar a incidência de inovação numa dada população empresarial de interesse sugere que essa é uma discussão ainda em construção. Alguns achados recaem principalmente na ocorrência de viés em testes de conceito de novos produtos em desenvolvimento - NPD (KLINK; ATHAIDE, 2006; LEES; WRIGHT, 2004). Entretanto, estudo de Blindenbach-Driessen et al. (2010), realizado com o objetivo de avaliar o desempenho de projetos de inovação, evidenciou a ocorrência de viés do informante gerado pela fonte gestor de inovação e líder do projeto.

O reconhecimento desse ambiente faz emergir a necessidade de procedimentos metodológicos sensíveis para detectar possíveis erros de compreensão do conceito de inovação por parte dos entrevistados, a fim que sejam previstos mecanismos para sua minimização no cômputo do erro total de mensuração de indicadores de inovação.

\subsection{Contexto}

A mensuração da ocorrência de inovação é relevante tanto na esfera privada quanto na pública. Para as empresas privadas, essa mensuração pode ser entendida como ferramenta estratégica para a busca ou manutenção de sua competitividade, enquanto para as autoridades governamentais, o conhecimento dessa medida é importante instrumento de apoio à formulação de políticas públicas para o desenvolvimento econômico (JARAMILLO; LUGONES; SALAZAR, 2001; ADVISORY..., 2008).

No entanto, Blindenback-Driessen et al. (2010) relatam que dados subjetivos obtidos em estudos sobre gestão de projeto são particularmente propensos a viés da 
informação dependendo do entrevistado. Entre os motivos do viés, está a possibilidade de parcialidade nas informações declaradas, seja pela situação em que o entrevistado não detém conhecimento sobre todo o processo investigado, seja pela influência da perspectiva ou posição do entrevistado na sua percepção de desempenho no projeto. Ainda segundo esses autores, os gestores da inovação parecem ser melhores informantes para avaliar o desempenho de produto, enquanto líderes de projeto de inovação são melhores informantes sobre aspectos do desempenho operacional do projeto, como cronograma e orçamento. Contudo, relatam os autores, nem líderes de projeto, nem gestores de inovação parecem ser confiáveis sobre suas percepçôes de qualidade e conhecimento adquirido.

Em paralelo, instrumentos consagrados no levantamento do ambiente de inovação tecnológica, especialmente no mercado brasileiro, como, por exemplo, o questionário utilizado pela Pesquisa de Inovação Tecnológica (Pintec), do Instituto Brasileiro de Geografia e Estatística (IBGE, 2010), evidenciam a complexidade do levantamento da realidade do ambiente de inovação tecnológica, na medida em que expõem conceitos orientadores dos questionamentos. No entanto, os conceitos apresentados podem ser interpretados de forma diferente, ou, em graus diferentes, por aqueles que participam dos levantamentos fornecendo esse tipo de dado da unidade empresarial.

\subsection{Problema de pesquisa e objetivo}

As considerações anteriores remetem à reflexão sobre o grau de precisão existente nos levantamentos voltados à mensuração da taxa de empresas inovadoras no mercado brasileiro, sob algum dos conceitos de inovação, quando estes são de natureza quantitativa, utilizando instrumentos de coleta de dados totalmente estruturados.

Sob essa orientação, o estudo buscou:

- formalizar um fluxo metodológico dos procedimentos utilizados para a detecção de erro de compreensão, por parte dos informantes, do conceito de inovação implícito na pergunta (Fluxo Metodológico para Detecção do Erro de Coleta dos Dados) e do fluxo metodológico para a correção do erro de coleta - dado originalmente observado (Fluxo Metodológico para Correção do Erro de Coleta );

- estimar a proporção de descrições de inovação de produto e a proporção de inovação em processo pertinentes ao conceito implícito utilizado na pergunta; 
- verificar se o procedimento metodológico de correção gera uma proporção de casos de inovação em produto e de inovação em processo estatisticamente menor do que a proporção observada (sem correção), confirmando a ocorrência de viés da informação sobre inovação e, consequentemente, corroborando a necessidade de utilização dos procedimentos metodológicos de correção do dado originalmente observado.

Para isso, foram examinados os dados de levantamento amostral de unidades empresariais do setor metal mecânico da região do Grande $\mathrm{ABC}$ paulista, que estudou a ocorrência de inovação em produto e em processo sob o conceito apresentado no Manual de Oslo (OCDE, 2005).

A próxima seção utiliza uma seleção de autores para descrever as diferentes abordagens sobre o conceito de inovação e os diferentes indicadores para sua medição nos diversos ambientes empresarias - grande, média e pequena empresa -, bem como evidencia dificuldades para a coleta de dados relativos a inovação inerentes ao ambiente empresarial à medida que o porte da empresa diminui. A seção 3 divide-se em duas partes. A primeira aborda o víes de mensuração como variante do erro total e busca consubstanciar a seleção do viés da informação enquanto fonte de erro não amostral alvo desse estudo, entre as fontes de erro que reduzem a precisão da pesquisa. A segunda parte discute sobre o uso de questões abertas como um mecanismo de minimização do erro não amostral. A seção 4 relata sobre os procedimentos metodológicos aplicados para a detecção e, posteriormente, para a correção dos dados observados relativos às declaraçôes sobre a ocorrência de inovação em produto e em processo, tendo como conceito implícito na pergunta o apresentado no Manual de Oslo (OCDE, 2005), formalizando esses procedimentos por meio da apresentação de dois fluxos metodológicos. A seção 5 apresenta os resultados sobre o segundo e o terceiro objetivos desse estudo, enquanto a seção 6 conclui sobre a contribuição da questão aberta enquanto mecanismo de identificação de eventual compreensão indevida do conceito implícito na pergunta sobre a ocorrência de inovação.

\section{0 ambiente teórico da inovação tecnológica: conceitos e indicadores para sua mensuração}

Embora não seja intenção desse estudo a discussão do conceito de inovação, a abordagem apresentada a seguir visa o reconhecimento de sua complexidade e, assim, sensibilizar os pesquisadores que utilizam surveys de inovação sobre a possibilidade de viés da informação por parte do respondente. 
Maria do Carmo Romeiro, Leandro Campi Prearo, Marco Antonio Pinheiro da Silveira, João de Paula Ribeiro Neto

Uma avaliação preliminar de trabalhos teóricos e pesquisas de natureza empírica sobre o tema inovação tecnológica revela a diversidade de conceitos e indicadores propostos para sua mensuração, o que tanto evidencia a complexidade de interpretação sobre essa questão entre os estudiosos como sugere a dificuldade de compreensão desses conceitos pelos informantes em levantamentos nas unidades empresariais.

\subsection{A diversidade de conceitos sobre inovação}

Diversas abordagens encontradas na literatura descrevem a inovação como um fenômeno social complexo, fruto da interação de vários atores, com influência sobre o desempenho de empresas e países (PACAGNELLA JR., 2006). A inovação influencia e é influenciada pela sociedade (HEGEDUS, 2006) e pelas características culturais da organização (GODOY, 2009). Nesse ambiente, as tentativas de classificação da inovação tendem a se multiplicar, como resposta ao aumento da complexidade e do conhecimento sobre o tema (HEGEDUS, 2006). Assim, a inovação pode ser vista num amplo espectro entre extremos, isto é, desde pequenas modificações, quase imperceptíveis aos usuários e ao processo produtivo, até mudanças que irão alterar o modo de vida da sociedade (HEGEDUS, 2006).

Bachmann e Destefani (2008) consideram que uma maneira simples e direta de definir as inovações tecnológicas é referir-se a essas como a utilização do conhecimento sobre novas formas de produzir e comercializar bens e serviços. Os autores informam que, por inovação tecnológica, Schumpeter (1883-1950) entendia cinco categorias de fatores: a fabricação de um novo bem; a introdução de um novo método de produção; a abertura de um novo mercado; a conquista de uma nova fonte de matéria-prima; e a realização de uma nova organização econômica, tal como o estabelecimento de uma situação de monopólio.

Aderente a essa abordagem, o conceito apresentado no Manual de Oslo, produzido pela Organização para Cooperação Econômica e Desenvolvimento (OCDE), editado em português pela Financiadora de Estudos e Projetos (Finep), em 2005, contempla as categorias de inovação em produtos e processos novos e aprimorados (TPP). O Manual destaca, também, a importância de se diferenciarem essas categorias de outras mudanças na empresa ou na indústria, como a mudança organizacional e outras modificaçōes em produtos e processos. 
Assim,

A empresa inovadora em TPP é uma empresa que tenha implantado produtos ou processos tecnologicamente novos ou aprimorados, ou combinaçôes de produtos e processos, durante o periodo em análise. Trata-se de empresa com atividades de inovação TPP bem-sucedidas durante o periodo. Uma empresa que tenha tido atividades de inovação TPP abortadas não se inclui, nem uma empresa que, ao final do periodo em análise tenha trabalho de inovação TPP em andamento que ainda não tenha resultado em implantação. (OCDE, 2005, p.70).

A inovação TPP pode ser discriminada entre produtos e processos, e por grau de novidade da mudança introduzida em cada caso. A inovação tecnológica de produto pode assumir duas formas abrangentes: produtos tecnologicamente novos e produtos tecnologicamente aprimorados. Inovação tecnológica de processo é a adoção de métodos de produção novos ou significativamente melhorados, incluindo métodos de entrega dos produtos (OCDE, 2005).

No entanto, Vilhena (2010), ao abordar resultados da Pesquisa sobre Inovação Tecnológica do IBGE - PINTEC 2008, menciona apontamentos da conferência Community Innovation Survey (CIS) de 2008, no sentido de retratar a necessidade ampliação do conceito de inovação, incorporando as inovações organizacionais e as de aplicação de estratégias de marketing (Figura 1).

FIGURA 1

Elementos para ampliação do conceito de inovação, apontados pelo CIS 2008

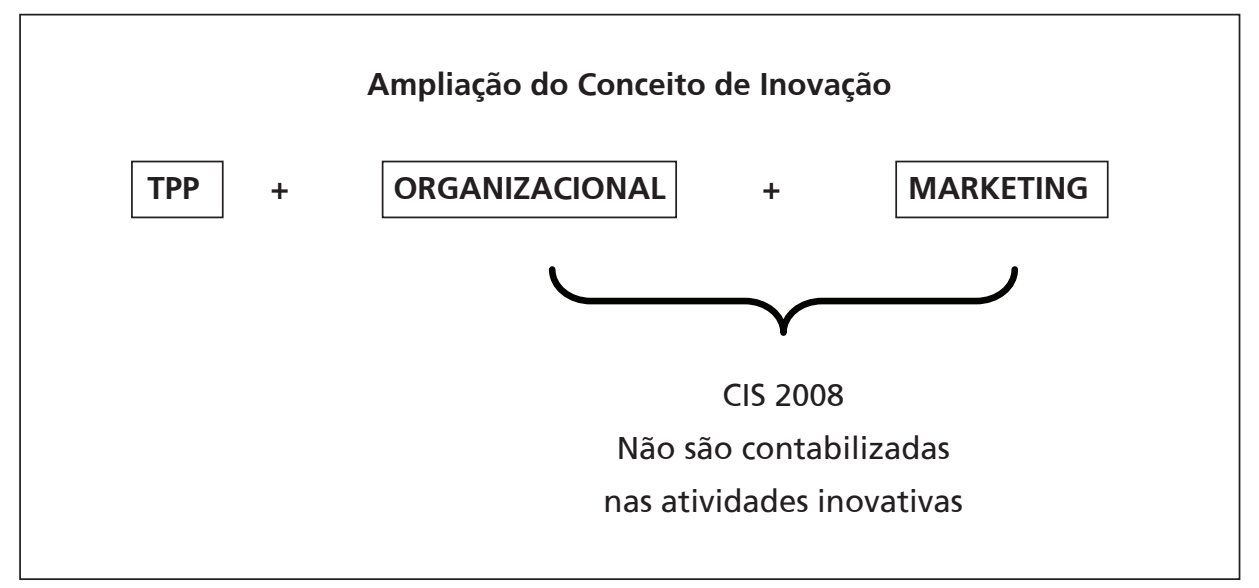

Fonte: Vilhena (2010).

Nota: TPP = Inovação em Produto e Processo. 
Maria do Carmo Romeiro, Leandro Campi Prearo, Marco Antonio Pinheiro da Silveira, João de Paula Ribeiro Neto

Ainda, Walker (2008) faz uma avaliação empírica dos tipos de inovação na área de serviços e propõe uma ferramenta que contempla dois tipos de inovação de processo: inovações de mercantilização e de organização. Mercantilização, segundo o autor, envolve a modificação de processos e sistemas operacionais da organização para aumentar a eficiência e eficácia na produção e distribuição dos serviços aos usuários. Já as inovações de organização ocorrem na estrutura, estratégia e processos administrativos, que incluem melhorias nas práticas de uma organização e a introdução de novas estruturas organizacionais. Inovaçôes de organização são, portanto, voltadas para a atividade de trabalho primária da organização e para mudanças no sistema social (WALKER, 2008).

\subsection{Indicadores e instrumentos utilizados para mensuração de Inovação Tec- nológica e suas limitações}

Estudos recentes sobre a mensuração da inovação tecnológica apresentam significativo incremento da tentativa de estabelecer indicadores dos diversos componentes da inovação e as suas inter-relaçôes. Diversos estudos tratam de vários tipos de indicadores que permitem direta ou indiretamente mensurar a inovação tecnológica, além de proporem taxonomias para a classificação das empresas inovadoras (PRADO, 2009; INACIO JR., 2008; OLIVEIRA, 2007). Entretanto, conforme alertado por Pacagnella (2006), a utilização destes indicadores deve levar em conta as vantagens e desvantagens de cada um deles diante das características das empresas que serão estudadas.

A verificação ou medição da ocorrência da inovação tecnológica em empresas, tanto do setor de manufatura como de serviços, vem sendo feita por meio principalmente da aplicação de surveys utilizando questionários estruturados.

Essa medição muito se apoiou na verificação da intensidade da atividade e Pesquisa e Desenvolvimento (P\&D) e do número de patentes obtidas pela empresa. No entanto, Arundel (2007) relata que o primeiro Community Innovation Survey (CIS), ocorrido em 1993, foi indiscutivelmente uma das mais importantes fontes de dados sobre inovação na época e que seu objetivo e de outras pesquisas de inovação baseadas na primeira edição do Manual de Oslo foi superar algumas das limitaçôes dos surveys de pesquisa e desenvolvimento (P\&D). Dois objetivos principais da conferência foram: fornecer dados sobre atividades inovadoras que não foram baseados em P\&D; e fornecer medidas de resultados da inovação, ampliando a discussão sobre procedimentos de mensuração da atividade de inovação. 
Nessa discussão, tem-se a abordagem de Kupfer e Rocha (2005), que buscam identificar determinantes setoriais do desempenho das empresas industriais brasileiras, a partir da consideração de três categorias de desempenho empresarial, mensuradas por meio de indicadores de inovatividade, produtividade e comércio exterior. Ao tratar da questão do esforço inovador, os autores afirmam que, num primeiro nível, este se dá no âmbito da empresa que realiza a atividade de Pesquisa e Desenvolvimento (P\&D). Mas ele lembram que o estudo realizado por Quadros et al. (2002) conclui que somente grandes empresas recorrem à $P \& D$ interna como fonte relevante de inovações, sendo essa a principal razão pela qual as empresas de maior porte apresentam um desempenho tecnológico significativamente melhor do que o grupo de médias e pequenas empresas.

Segundo Arundel (2007), a política europeia depende, em grande medida, dos indicadores estabelecidos para P\&D. Para o autor, estes indicadores são excelentes medidas de atividades criativas formais para desenvolver inovações in-house, particularmente na indústria de transformação e, por isso, ele examina porque indicadores de P\&D ainda dominam as políticas de inovação na Europa, fazendo várias sugestóes para melhorar a utilidade da CIS. Diversos exemplos de novos indicadores são fornecidos, incluindo uma medida de resultado com melhor comparabilidade internacional, um indicador de difusão do conhecimento e um conjunto de indicadores para as capacidades de empresas inovadoras.

Particularmente para o ambiente de pequenas e médias empresas, Bachmann e Destefani (2008) propõem uma metodologia, baseada nas 12 dimensões da inovação descritas por Mohanbir Sawhney, da Kellogg School of Management (EUA), que permite avaliar o grau de maturidade inovadora das organizações de pequeno porte. Segundo estes autores, os indicadores tradicionalmente usados para medir o grau de inovação nas organizaçóes, como "número de patentes" e "percentual do faturamento aplicado em $\mathrm{P} \& \mathrm{D}$ ", não são adequados às micro e pequenas empresas.

O instrumento elaborado por Bachmann e Destefani (2008) para operacionalizar o cálculo do grau de inovação para MPEs se baseou, predominantemente, na ferramenta denominada Radar da Inovação, definida por Sawhney (2006), que relaciona as dimensóes pelas quais uma empresa pode procurar caminhos para inovar. O Radar da Inovação reúne as seguintes dimensōes:

- as ofertas criadas (a empresa lançou, com sucesso, algum novo produto no mercado nos últimos três anos?); 
- plataforma (a empresa oferece mais de um produto usando os mesmos componentes ou módulos?);

- marca (a marca da empresa é registrada? A empresa fez um novo uso de sua marca - em outro tipo de produto ou negócio?);

- clientes (a empresa adota alguma prática de relacionamento ou pesquisa sistemática para identificar as necessidades do mercado ou dos clientes?);

- soluções (a empresa ofertou algum novo produto complementar a seus clientes, criando nova oportunidade de receita?);

- relacionamento (a empresa adotou alguma facilidade ou recurso - senhas, cafezinho, vitrine, etc. - para melhorar o relacionamento com os clientes?);

- agregação de valor (a empresa identificou e adotou novas formas de gerar receitas usando os produtos e processos já existentes?);

- processos (a empresa alterou seus processos para obter maior eficiência, qualidade, flexibilidade ou menor ciclo de produção?);

- organização (alterações no organograma? Reorganização para ganhar agilidade ou qualidade?);

- cadeia de fornecimento (a empresa adotou alguma ação para reduzir o custo do transporte ou dos estoques de matéria-prima ou de produtos? Adotou alguma solução para melhorar o fluxo de informaçôes?);

- presença / praça (a empresa criou pontos ou canais de venda diferentes dos usuais?);

- rede (a empresa adotou alguma nova forma de ouvir ou falar com os clientes, usando ou não a tecnologia da informação?)

- ambiência de inovação (fração da equipe que é composta por profissionais que têm formação voltada para a pesquisa).

O instrumento de pesquisa elaborado por Bachmann e Destefani (2008) para PMEs considera que a inovação é fruto de um processo de inovação. Daí a preocupação dos autores em avaliar não o simples resultado (número de inovações), mas sim a maturidade dos processos de inovação das empresas. A ideia é dar um escore maior àquelas empresas que têm uma prática estruturada visando a inovação. Para escolher a escala, Bachmann e Destefani (2008) buscaram inspiração em diversos modelos usados para medir o grau de maturidade de processos, como os modelos de maturidade de projetos e o Modelo de Maturidade da Capacidade CMM (Capability Maturity Model). Para a medição objetiva do grau de inovação, foi desenvolvida uma escala reduzida para três situaçôes, visando classificar as empresas em "pouco ou nada inovadoras", "inovadoras ocasionais" e "inovadoras sistêmicas". Os autores 
identificaram a necessidade de se estabelecer um período de tempo para avaliação do grau de inovação das PMEs. Eles propõem um horizonte de três anos para o levantamento dos dados

A Pintec, um dos mais importantes instrumentos de estudo do ambiente de inovação tecnológica no Brasil, objetiva conhecer e mensurar o processo inovativo realizado pelas empresas brasileiras. Segundo Vilhena (2008), já houve quatro edições da Pintec - 2000 (período 1998-2000); 2003 (período 2001-2003); 2005 (período 2003-2005); e 2008 (período 2006-2008), cujos resultados foram divulgados em $09 / 2010$.

Essa pesquisa toma como referência conceitual e metodológica a orientação do Manual de Oslo de 2005, no modelo da CIS versão 2008, para o levantamento da inovação tecnológica de produto e de processo (TPP). O Manual é estruturado utilizando questôes fechadas para a identificação da ocorrência ou não de inovações em produto e em processo, precedidas da apresentação do conceito implícito da pergunta. Este conceito deve ser observado pelo respondente para que se posicione sobre a unidade estatística, ou seja, a entidade para a qual os dados solicitados são compilados. Complementarmente, a questão fechada é sucedida de questão aberta na qual o entrevistado apresenta breve descrição da inovação realizada. Sobre o tratamento dado à questão aberta não há registros no Manual da Pintec.

Destaque-se, ainda, que dados obtidos pela Pintec demonstraram que, quanto menor o porte da empresa, menor a taxa de inovação, caracterizada como a introdução de pelo menos um produto ou processo tecnologicamente novo ou substancialmente aprimorado. Adicionalmente, as empresas com 10 a 49 pessoas ocupadas aumentaram a taxa de inovação da primeira para a segunda edição, mas a reduziram no terceiro triênio pesquisado (respectivamente, 1998-2000, 2001-2003 e 2003-2005) (SEBRAE, 2007).

Entre as principais causas identificadas para estes resultados, estão a falta de compreensão das empresas sobre a importância da inovação, visto que não a percebem como elemento alimentador da longevidade dos seus negócios, a falta de cultura de inovação, visão de negócio associada a uma perspectiva operacional e de curto prazo, e o desconhecimento sobre as questões tecnológicas que envolvem suas áreas de atuação (COMITÊ DE TECNOLOGIA E INOVAÇÃO, 2007).

Acrescenta-se ao conjunto de causas o aspecto comportamental de gestores dessas empresas de menor porte, o qual estaria limitado por um conjunto específico de rotinas organizacionais acumuladas ao longo do tempo, de abrangência relativamente pequena, circunscrito a um paradigma tecnológico específico que tenderia 
a condicionar atitudes e visão de mundo (GODOY, 2009; INACIO JR., 2008; COMITÊ DE TECNOLOGIA E INOVAÇÃO, 2007).

Essa abordagem reforça a premissa de que, na relação pergunta-resposta de um levantamento sobre a ocorrência de inovação, diferentemente de um experimento, em que é possível exercer controle sobre um grande número de variáveis, haverá sempre condicionantes incontroláveis. Conforme Berndt e Oliveira (2005, p. 12), essas condicionantes não controladas compreendem "desde a homogeneidade (ou não) do compreensão de uma mesma palavra por diferentes respondentes, até o desejo mais ou menos explicito destes darem (ou não) as respostas verdadeiras".

\subsection{Evidências extraídas}

Como evidenciado nesse tópico, a definição do conceito de inovação tecnológica e de seus componentes é alvo de vários esforços de pesquisadores. Apesar da diversidade de conceitos encontrada, o Manual de Oslo é a principal fonte internacional de diretrizes para a coleta e uso de dados sobre atividades inovadoras da indústria (OCDE, 2005). Assim, há convergência de uso de sua proposta conceitual de inovação em produto e em processo como conceito implícito para a mensuração de inovação tecnológica, o que possibilita a comparação de resultados entre os países.

Também foram evidenciadas diferentes condicionantes incontroláveis presentes no ambiente organizacional e no comportamento individual do respondente que podem gerar erro não amostral.

Nesse contexto, justifica-se a importância de se reconhecerem as dificuldades de mensuração da inovação em levantamentos, tendo como uma das causas a compreensão imprecisa do conceito implícito na pergunta sobre a ocorrência de inovação em produto e em processo, por parte dos respondentes e, de forma mais acentuada, nas empresas de pequeno porte.

\section{Viés de mensuração e o uso de questões abertas para sua redução}

\subsection{Viés de mensuração de fontes de erro não amostral}

Conforme Tourangeau (2003), a partir da década de 1980, a metodologia de levantamento sofreu uma mudança de paradigma, no sentido de focar as causas dos erros de levantamento, motivada principalmente pela aplicação de métodos e conceitos da 
psicologia cognitiva para a redução do erro de mensuração em levantamentos - o desenvolvimento de novos métodos de coleta de dados e o aumento da preocupação sobre mensuração e não-resposta. Ainda, segundo o autor, o novo paradigma tem pouco a dizer sobre erro amostral, tópico central do velho paradigma, estando mais preocupado em mostrar como reduzir ou prevenir erros. Assim, os dois paradigmas se complementam.

Nesse contexto, o viés é uma das duas variantes em que se divide o erro total de levantamento (TSE) e diz respeito aos erros sistemáticos oriundos, principalmente, dos critérios de mensuração classificados na vertente não amostral da estrutura de catalogação das fontes de erro. A outra variante refere-se à variância que se origina, sobretudo, de procedimentos amostrais e diminui à medida que as amostras crescem (KISH, 1977 apud BERNDT; OLIVEIRA, 2005; SMITH, 2011). Enquanto a variância não tem qualquer impacto nos valores médios esperados das estimativas do verdadeiro, o viés ou erro sistemático altera a média das estimativas dos levantamentos (SMITH, 2011).

O TSE refere-se à acumulação de todos os erros que possam surgir na concepção, coleta, processamento e análise dos dados da pesquisa. Neste contexto, um erro de levantamento é definido como o desvio de uma resposta de pesquisa (estimativa do levantamento) do valor verdadeiro do parâmetro subjacente (BIEMER, 2010).

Smith (2011, p. 468) apresenta uma ampla abordagem sobre o TSE, alertando que, "primeiro, as pesquisas são instrumentos complexos com muitos componentes e, segundo, há vários caminhos alternativos para categorização do erro". O autor ratifica seu alerta por meio do exame das descrições sobre o erro em pesquisas apresentadas por Deming (1944), Hansen, Hurwitz e Madow (1953), Kish (1965), Brown (1967), Groves (1989), Smith (1996), Biemer e Lyberg (2003) e Alwin, 2007 (apud SMITH, 2011, p. 468).

O autor busca um refinamento da perspectiva do erro total em levantamentos, ilustrando-o por meio de um diagrama (Figura 2) que toma por premissa que os componentes de uma pesquisa podem estimular ou desestimular erros, seja viés ou variância, ou mesmo uma combinação de ambos, o que leva alguns aspectos a duas localizações no diagrama. A construção apresentada por Smith (2011) é bastante útil no sentido de evidenciar as possíveis fontes de erro, contribuindo para a definição de procedimentos voltados para a minimização do erro de natureza amostral ou não amostral. 
Maria do Carmo Romeiro, Leandro Campi Prearo, Marco Antonio Pinheiro da Silveira, João de Paula Ribeiro Neto

FIGURA 2

Refinando a perspectiva do erro total de levantamento

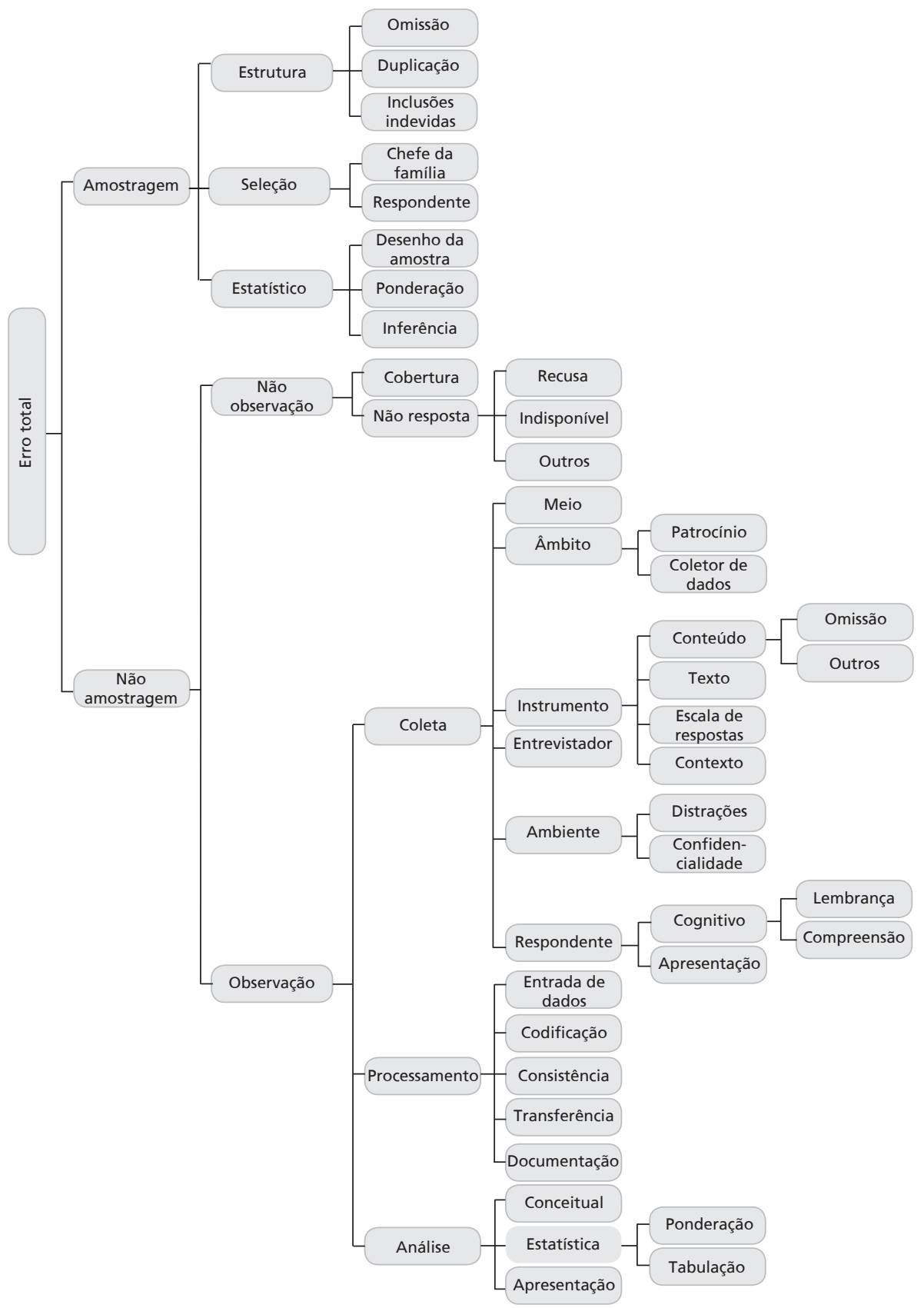

Fonte: Adaptado de Smith (2011, p. 467)

146 Revista Brasileira de Inovação, Campinas (SP), 13 (1), p. 133-162, janeiro/junho 2014 
Ainda que alguns tipos de erros, como variância amostral, sejam inevitáveis nos levantamentos por amostragem, outros, como viés de não resposta ou viés de coleta devido ao respondente, poderiam ser teoricamente eliminados, mas na realidade apenas podem ser minimizados mediante o uso de melhores práticas envolvendo essas fontes de erro (SMITH, 2011).

É nesse sentido que o presente estudo busca reconhecer a possibilidade de erro do respondente ou informate em função da compreensão imprecisa do conceito de inovação e apresentar procedimentos que contribuam para sua minimização.

Sob a orientação da teoria do erro total de levantamento, nesse estudo uma possível redução do erro total de levantamento estaria circunscrita à sua dimensão não amostral, na componente erro de observação, no âmbito da coleta de dados fonte respondente -, decorrente de cognição, em especial a compreensão indevida do conceito de inovação, sendo esse roteiro do erro que deve orientar a definição dos procedimentos metodológicos para sua minimização, explicitando a forma de detectar os casos de sua ocorrência e a forma de tratá-lo.

Nesse contexto, a fonte instrumento de coleta de dados é inerente ao processo, visto que a presença de questão aberta no instrumento de coleta de dados, conforme abordagem no tópico seguinte, é condição essencial no fluxo de procedimentos metodológicos para minimização do erro de mensuração dos indicadores de inovação.

Embora outras fontes de erro estejam presentes na componente erro de observação, no âmbito da coleta de dados, como as condiçôes do ambiente de coleta e a atuação do entrevistador, essas não são foco do presente estudo. Da mesma forma, embora a "lembrança" (ou a ausência de lembrança) seja outro aspecto indutor de viés do respondente, também essa não é foco desse estudo.

Considerando o caminho do viés de mensuração mostrado na Figura 2, no âmbito desse estudo, a hipótese a ser verificada refere-se à ocorrência de superestimação da taxa de empresas inovadoras medida pelas questôes fechadas que tratam do levantamento de inovação, em decorrência da impossibilidade de se detectar a compreensão indevida do conceito de inovação pelos respondentes que declaram que a unidade empresarial (unidade de investigação segundo as notas técnicas da Pintec - IBGE, 2010 ou unidade estatística segundo o Manual de Oslo, OCDE2005) realizou inovação em produto e/ou em processo.

O não tratamento dos casos de resposta negativa sobre a realização de inovação apoiou-se na abordagem de Sakshaug et al. (2010), que relatam que itens que perguntam sobre comportamentos socialmente indesejáveis (por exemplo, uso de drogas ilícitas) são altamente suscetíveis a erros de medição, mas menos suscetíveis 
Maria do Carmo Romeiro, Leandro Campi Prearo, Marco Antonio Pinheiro da Silveira, João de Paula Ribeiro Neto

a erros de não-resposta. Por outro lado, itens que investigam sobre comportamentos socialmente desejáveis (por exemplo, consumo consciente) são um pouco menos propensos a erros de medição comparativamente aos anteriores, mas também podem ser mais suscetíveis a erros de não-resposta, uma vez que aqueles que pertencem à categoria desejável (por exemplo, consumidores conscientes) são mais propensos a tornarem-se entrevistados do que os da categoria indesejável.

Nesse sentido, admitindo-se que a inovação seja um comportamento desejável e, portanto, mais sujeito à não-resposta, a ausência dessa situação no processo de coleta sugere que os participantes da pesquisa julgam-se pertencentes à categoria desejável. Nesse contexto, a declaração da não ocorrência de inovação dar-se-ia de forma consciente, o que dificultaria investigar a realização de algo que o respondente não supõe ter realizado.

\subsection{Uso de questões abertas}

Ainda que as medidas objetivas sejam claramente preferidas pelos pesquisadores, por vezes os informantes não têm conhecimento adequado do tema tratado a ponto de gerar um resultado confiável (ERNST, 2001 apud BLINDENBACH-DRIESSEN et al., 2010).

Cooper e Schlinder (2003) afirmam que o questionamento é a abordagem mais eficiente e econômica para se reunirem dados primários. Seu principal ponto fraco quanto à qualidade e quantidade de informações obtidas é a dependência da capacidade e da disposição dos respondentes de cooperar.

Mesmo que os respondentes participem, eles podem não ter o conhecimento exigido ou não ter uma opiniāo sobre o assunto em questão... Muitas vezes os respondentes se acham obrigados a expressar uma opiniāo, mesmo quando não têm uma... Os respondentes também podem interpretar uma questão ou um conceito de forma diferente da que foi pretendida pelo pesquisador (COOPER; SCHLINDER, 2003).

Hair Jr. et al. (2005) afirmam sobre a utilização de perguntas abertas:

As questôes abertas são relativamente fáceis de se elaborar porque o pesquisador não precisa oferecer com antecedência as alternativas de resposta. Na verdade, quando o pesquisador não conhece as possiveis respostas, como numa pesquisa exploratória, só é possivel fazer perguntas abertas. Elas também são úteis quando o pesquisador acredita 
que as alternativas podem influenciar a resposta... As perguntas abertas geralmente seguem-se a uma pergunta inicial, independente desta ser aberta ou fechada.

O'Cathain e Thomas (2004) classificam em quatro tipos as perguntas que podem exigir uma resposta aberta ao invés de fechada: extensão, substituição, expansão e geral. As perguntas do tipo extensão são utilizadas ao final de uma lista de opções de resposta, para assegurar que todas as possibilidades estão representadas. As do tipo substituição são utilizadas quando perguntas abertas substituem as fechadas. As perguntas abertas do tipo expansão são utilizadas em sequência a uma questão fechada, sendo os respondentes convidados a elaborar a resposta dada nesta questão fechada. Estas perguntas têm o papel de explicar, esclarecer ou expandir as respostas dadas às questôes estruturadas/fechadas. Por fim, nas questôes gerais, os entrevistados são convidados a se manifestarem sobre sua experiência em relação ao tema da pesquisa.

Os instrumentos de coleta de dados com foco na mensuração da inovação tecnológica consagrados pela literatura privilegiam abordagens que favorecem a quantificação estruturada das ocorrências e o tratamento estatístico dos dados apresentados sobre inovação (IBGE, 2010; OCDE, 2007; 2005; 1995). Assim, tais instrumentos tendem a apresentar uma predominância de questôes fechadas em sua estruturação, que implicariam a possibilidade de vieses por ocasião da coleta de dados junto às organizações de pequeno porte.

Nesse estudo, a utilização da questão aberta do tipo expansão mostra-se adequada para dar sequência à elaboração da resposta afirmativa em relação ao questionamento sobre a realização de inovação pela unidade empresarial no período de referência, descrevendo o(s) evento(s) de inovação ocorrido(s). No entanto, seu uso não se mostra adequado para elaboração da resposta negativa sobre ocorrência de inovação na unidade empresarial.

\section{Procedimentos metodológicos}

Este estudo é de natureza descritivo-conclusiva e foi delineado utilizando-se parte de um levantamento realizado em empresas do setor metal-mecânico da Região do Grande ABC.

Os dados compuseram a Pesquisa de Diagnóstico da Oferta e da Demanda de Serviços Tecnológicos das Empresas do Setor Metal-Mecânico do Grande ABC, doravante identificada por Pesquisa Setorial, realizada pela Agência de De- 
senvolvimento Econômico do Grande ABC, sob o patrocínio do Sebrae, Banco Interamericano de Desenvolvimento (BID) e Governo da Região de Marchi (Itália) (AGÊNCIA..., 2009).

A Pesquisa Setorial foi realizada por meio de amostragem probabilística sistemática de 500 empresas da Região do Grande $\mathrm{ABC}$, de micro, pequeno, médio e grande portes, a partir de um cadastro de 3.000 empresas do setor metal-mecânico, com predominância daquelas de micro e pequeno portes, as quais foram consideradas população-alvo do estudo. Contudo, o recorte dessa amostra somente para as empresas de micro e pequeno portes reduz o número de casos a ser estudado a 418 unidades industriais.

A íntegra da coleta de dados ocorreu por meio de entrevista pessoal, com duração aproximada de 120 minutos, durante os meses de agosto a outubro de 2009. Contudo, o recorte em inovação TPP, concentrou a coleta de dados em torno de 15 minutos.

A descrição do procedimento metodológico para detecção de possível erro de coleta é apresentada na Figura 3, por meio de um fluxo de procedimentos, o qual é complementado na sequência pela descrição dos conteúdos das questões fechada e aberta utilizadas no levantamento de cada tipo de inovação - produto e processo.

FIGURA 3

Fluxo metodológico para detecção do erro de coleta de dados sobre inovação em produto e inovação em processo

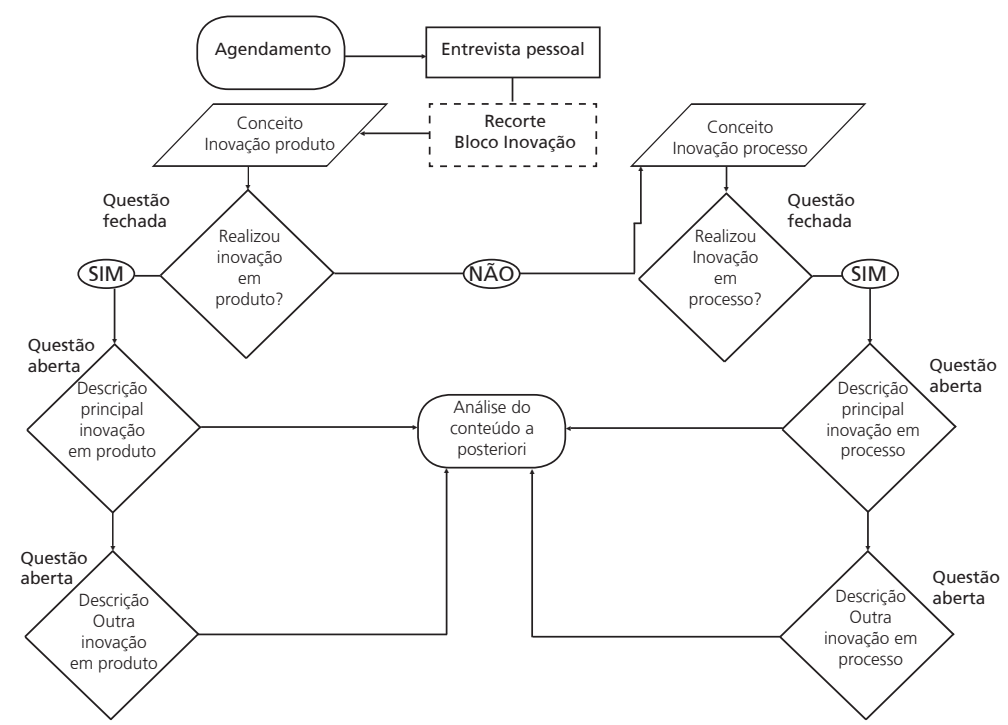

Fonte: Elaboração dos autores. 
O conceito de inovação tecnológica que orientou o levantamento da Pesquisa Setorial foi o divulgado pelo Sebrae (2007), com base no Manual de Oslo (OCDE, 2005), que também orienta a Pesquisa de Inovação Tecnológica do IBGE (Pintec), ou seja,

A inovação tecnológica é a concepção de novo produto ou processo de produção, bem como a agregação de novas funcionalidades ou características ao produto ou processo que impliquem melhorias incrementais e efetivo ganho de qualidade ou produtividade, resultando maior competitividade no mercado (SEBRAE, 2007).

A estrutura de questionamento sobre inovação tecnológica presente no instrumento de coleta de dados utilizado pela Pesquisa Setorial apresentou inicialmente aos respondentes o conceito geral de inovação em produto e em processo, em momentos distintos, conforme ilustrado a seguir.

Neste levantamento, uma Inovação Tecnológica é definida pela introdução no mercado de um produto tecnologicamente novo ou substancialmente aprimorado ou pela introdução de um processo produtivo tecnologicamente novo ou substancialmente aprimorado. Inicialmente vamos falar sobre Inovação de Produto e para isso, são consideradas duas situaçôes: uma, que compreende produtos ou serviços tecnologicamente novos e, outra, que compreende produtos ou serviços tecnologicamente aperfeiçoados.

Considere que um Produto ou Serviço tecnologicamente novo é aquele cujas caracteristicas fundamentais, ou seja, especificaçōes técnicas, matérias-primas, componentes, software, funçōes de uso do software diferem significativamente de todos os produtos previamente produzidos pela empresa. Por outro lado, um produto ou serviço tecnologicamente aperfeiçoado refere-se àquele produto ou serviço previamente existente, cujo desempenho foi substancialmente incrementado ou aperfeiçoado, através de mudanças nas matérias primas, componentes ou em outras características que melhoram seu desempenho (AGÊNCIA..., 2009)

Após a apresentação do conceito de inovação em produto ou serviço, o entrevistado foi solicitado a informar sobre a ocorrência deste tipo de inovação, respondendo a uma pergunta fechada, dicotômica (Não ou Sim), conforme ilustrado a seguir: 
Maria do Carmo Romeiro, Leandro Campi Prearo, Marco Antonio Pinheiro da Silveira, João de Paula Ribeiro Neto

Considerando essas definiçōes, a empresa introduziu produto tecnologicamente novo ou significativamente aperfeiçoado, mas já existentes no mercado nacional?

Considerando essas definições, a empresa introduziu produto tecnologicamente novo ou significativamente aperfeiçoado, não existente ainda no mercado nacional?

A resposta negativa às duas indagações direcionou o entrevistado para se manifestar sobre inovação em processo, enquanto a resposta afirmativa a pelo menos uma delas motivou a aplicação de pergunta aberta com a função de expansão, permitindo ao respondente elaborar a resposta explicativa ou esclarecedora da resposta afirmativa apresentada na questão anterior, ou seja, o entrevistado descreveu a inovação em produto que orientou sua indicação afirmativa à questão.

Qual o produto tecnologicamente novo ou substancialmente aperfeiçoado lançado por essa empresa de 2006 para cá?

Na sequência, buscou-se aprofundar a ocorrência de inovação questionando-se sobre a ocorrência de algum outro procedimento de inovação em produto.

O mesmo formato de questionamento foi utilizado para o levantamento de dados sobre inovação em processo, tendo como texto conceitual o que segue.

Processos tecnologicamente novos ou substancialmente aprimorados envolvem a introdução de tecnologia de produção nova ou significativamente aperfeiçoada, assim como métodos novos ou substancialmente aprimorados para manuseio e entrega de produtos (acondicionamento e preservação). Esse processo deve ser significativo em termos: do nivel de produto, qualidade do produto ou custos de produção ou entrega. A introdução desse processo pode ter por objetivo a produção ou entrega de produtos tecnologicamente novos ou substancialmente novos ou substancialmente aprimorados, que não possam utilizar os processos previamente existentes, ou simplesmente aumentar a eficiência da produção e da entrega de produtos já existentes. Não estão incluidas: mudanças pequenas ou rotineiras nos processo existentes, mudanças puramente administrativas ou organizacionais e mudanças ou criação de redes de distribuição (AGÊNCIA..., 2009).

A informação sobre inovação em processo deu-se a partir do uso de pergunta fechada dicotômica (Não ou Sim), seguida da questão aberta para descrição da 
ocorrência em caso de posicionamento afirmativo sobre inovação em processo, conforme apresentado a seguir.

Então, considerando essas definiçōes, de jan/2006 a dez/2008, a empresa introduziu processo tecnologicamente novo ou significativamente aperfeiçoado para a empresa, mas já existentes no mercado nacional? 1.Não 2.Sim

E de jan/2006 a dez/2008, a empresa introduziu processo tecnologicamente novo ou significativamente aperfeiçoado, mas ainda não existente no mercado nacional?

A ocorrência de posição afirmativa conduziu o entrevistado para a questão aberta (Qual o principal processo tecnologicamente novo ou substancialmente aperfeiçoado, lançado por sua empresa de 2006 pra cá?), na qual era descrita a inovação que pautou a indicação afirmativa do entrevistado.

A pesquisa realizada neste trabalho consiste na análise das respostas às questôes abertas que descreveram a inovação tecnológica apresentada pelos respondentes. Trata-se, portanto, de um subproduto da Pesquisa Setorial. Destaque-se que o resultado apresentado no documento oficial da Pesquisa Setorial, relativo às ocorrências de inovação, foi apurado à luz de um ajuste para a declaração positiva do informante quando a pergunta aberta revelou o contrário.

O procedimento adotado, então, especificamente para atender ao presente estudo, pode ser descrito nos seguintes passos:

- passo 1 - seleção dos formulários com respostas afirmativas sobre inovação em produto e/ou em processo nas questôes fechadas;

- passo 2 - análise do conteúdo manifestado pelo entrevistado na questão de expansão em cada caso;

- passo 3 - codificação do conteúdo em: pertinente; não pertinente; e compreensão equivocada sobre o tipo de inovação ocorrida (inovação declarada descreveu inovação em processo quando abordado sobre inovação em produto ou inovação declarada descreveu inovação em produto quando abordado sobre inovação em processo).

A Figura 4 ilustra o fluxo metodológico para a correção do erro da informação, utilizando a análise dos conteúdos presentes na descrição das ocorrências de inovação em produto e em processo. 
Maria do Carmo Romeiro, Leandro Campi Prearo, Marco Antonio Pinheiro da Silveira, João de Paula Ribeiro Neto

FIGURA 4

Fluxo metodológico para correção do erro de coleta de dados a partir da análise do conteúdo presente na descrição da ocorrência de inovação em produto e em processo

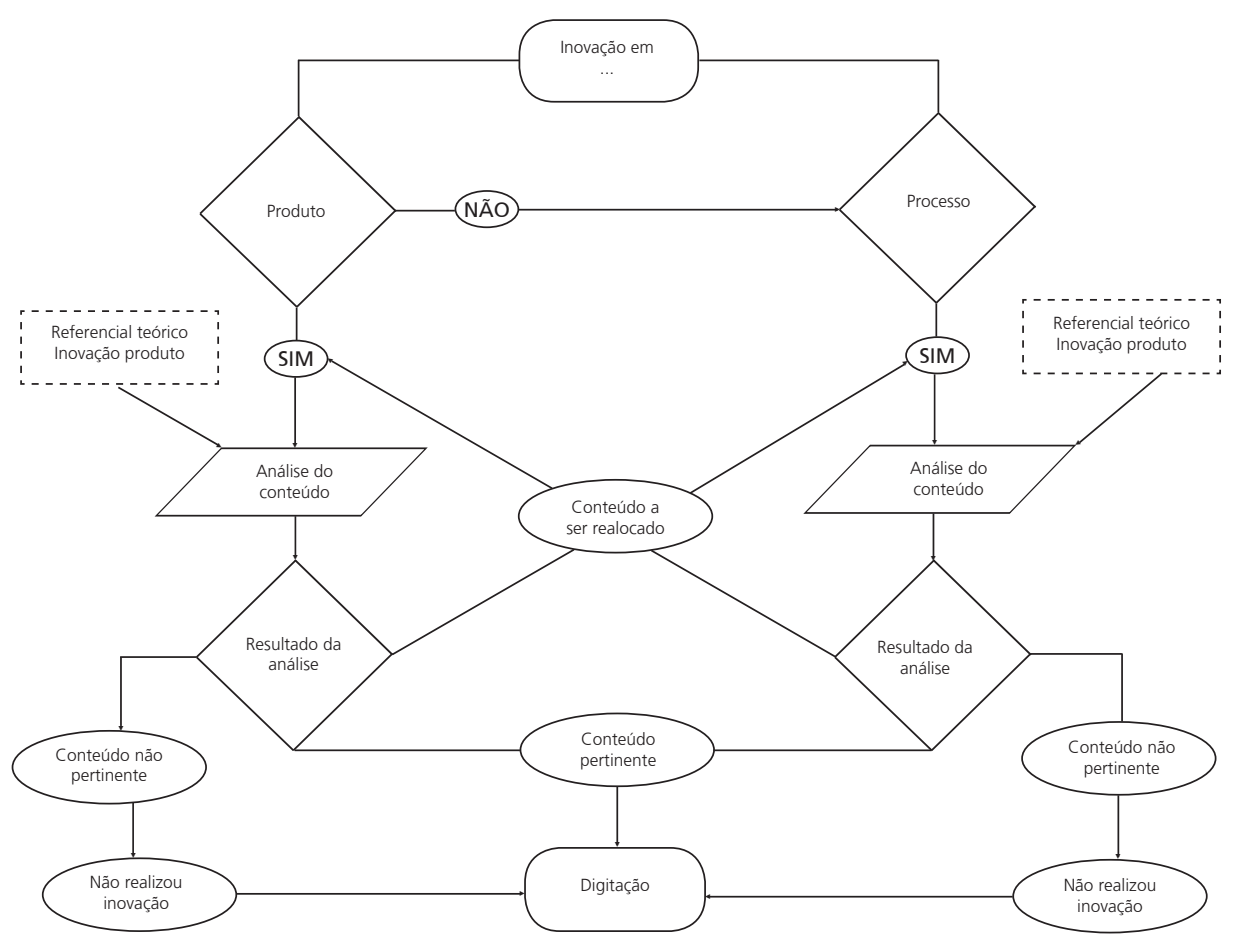

Fonte: Elaboração dos autores.

\section{Resultados}

A título de ilustrar a ocorrência de compreensão imprecisa do conceito implícito na pergunta sobre inovação em produto e em processo, considere-se o exemplo de respondente que declarou ter realizado inovação tecnológica na modalidade produto e que, em resposta à questão de expansão (questão aberta), declarou o seguinte conteúdo: implantação de corte a laser com máquina CNC - computadorizada usando Windows [...] lê desenhos e transfere para a peça. A análise desse conteúdo, realizada posteriormente pelo grupo de pesquisa, resultou no reposicionamento da modalidade de inovação tecnológica de produto para processo. Outro exemplo refere-se ao caso de respondente que declarou a realização de inovação tecnológica na modalidade 
processo, mediante o seguinte relato na questão de expansão: instalação de botoeira inteligente no equipamento que é utilizado em semáforo [...] antes bipava (fazia um barulho) e, agora, fala [...] mais adequado para pessoas com problema grave de visão [...] o equipamento é instalado na coluna do semáforo. A análise desse conteúdo concluiu por inovação tecnológica na modalidade produto, em vez de processo, e, portanto, alterou a codificação da coleta do dado inicialmente declarado pelo respondente, ou seja, a codificação da questão relativa à ocorrência de inovação em processo passa de "sim" para "não" e a codificação da questão relativa à ocorrência de inovação em produto passa de "não" para "sim". Outro exemplo refere-se ao caso de declaração de realização de inovação em processo, decorrente da implantação de sistema de informatização administrativa e financeira, conforme declaração do respondente. A análise desse conteúdo concluiu pela não ocorrência de inovação tecnológica, alterando novamente a codificação da coleta do dado inicialmente declarado pelo respondente.

Outros exemplos de compreensão imprecisa dos conceitos de inovação tecnológica em produto e em processo, identificada a partir da análise do conteúdo da resposta apresentada na questão de expansão, que solicitou a descrição da inovação realizada, são ilustrados no Quadro 1.

Foram submetidos à análise de conteúdo 161 questionários com declaraçōes afirmativas sobre a realização de inovação em produto, dos quais 127 apresentaram declarações pertinentes à modalidade indicada pelo entrevistado, oito registraram descrições de inovação em processo, em vez de inovação em produto, e 26 continham declarações não pertinentes à inovação tecnológica.

Em outros 174 casos com declarações afirmativas sobre a realização de inovação em processo, submetidos à análise de conteúdo, 153 foram confirmados com declarações pertinentes e 21 com declaraçôes não pertinentes à inovação tecnológica.

Portanto, do total de 335 casos de indicações de realização de inovação tecnológica, $280(83,6 \%)$ apresentaram compreensão precisa dos conceitos de inovação tecnológica tratados pela pesquisa, oito $(2,4 \%)$ mostraram-se imprecisos quanto à modalidade de inovação realizada, enquanto $47(16,0 \%)$ apresentaram declarações não pertinentes à inovação tecnológica. A Tabela 1 ilustra os números das ocorrências decorrentes da análise do conteúdo das descrições. 
Maria do Carmo Romeiro, Leandro Campi Prearo, Marco Antonio Pinheiro da Silveira, João de Paula Ribeiro Neto

\section{QUADRO 1}

Resultado do cotejamento entre a modalidade de inovação tecnológica declarada e a descrição da ação considerada como inovação pelo entrevistado de unidades do setor metal-mecânico Região do Grande ABC - 2009

\begin{tabular}{|c|c|c|}
\hline $\begin{array}{l}\text { Modalidade de } \\
\text { inovação tecnológica } \\
\text { declarada pelo } \\
\text { entrevistado } \\
\end{array}$ & Inovação citada & Resultado \\
\hline Produto & $\begin{array}{l}\text { Implantação de corte a laser - máquina } \\
\text { CNC - computadorizada usa Windows [...] } \\
\text { lê desenhos e transfere para a peça [...] }\end{array}$ & $\begin{array}{l}\text { Recodificado para } \\
\text { processo }\end{array}$ \\
\hline Produto & Aquisição da máquina CNC de usinagem & $\begin{array}{l}\text { Recodificado para } \\
\text { processo }\end{array}$ \\
\hline Produto & $\begin{array}{l}\text { Informatização e automação da produção. } \\
\text { Máquinas que eram manuais, agora são } \\
\text { informatizadas }\end{array}$ & $\begin{array}{l}\text { Recodificado para } \\
\text { processo }\end{array}$ \\
\hline Produto & $\begin{array}{l}\text { Implantação de tecnologia de usinagem } \\
\text { - CNC }\end{array}$ & $\begin{array}{l}\text { Recodificado para } \\
\text { processo }\end{array}$ \\
\hline Produto & $\begin{array}{l}\text { Instalação de encaixotadora automática } \\
\text { de caixas }\end{array}$ & $\begin{array}{l}\text { Recodificado para } \\
\text { processo }\end{array}$ \\
\hline Produto & $\begin{array}{l}\text { Agora no tratamento térmico temos uma } \\
\text { receita para cada peça. As peças têm seus } \\
\text { ciclos de tratamento e agora é feito por } \\
\text { controle pelo sistema CNC }\end{array}$ & $\begin{array}{l}\text { Recodificado para } \\
\text { processo }\end{array}$ \\
\hline Produto & $\begin{array}{l}\text { Fazíamos a mola de torção manualmente } \\
\text { e hoje é o sistema pneumático e grampo } \\
\text { de aço (não é CNC) Precisa do homem } \\
\text { alimentando a máquina e controlando } \\
\text { (antes usávamos prensa) }\end{array}$ & $\begin{array}{l}\text { Recodificado para } \\
\text { processo }\end{array}$ \\
\hline Produto & $\begin{array}{l}\text { Usinagem (CNC) - Melhorou na } \\
\text { quantidade e custo do produto }\end{array}$ & $\begin{array}{l}\text { Recodificado para } \\
\text { processo }\end{array}$ \\
\hline Produto & $\begin{array}{l}\text { Instalação de software de CAD e CAM, } \\
\text { com isso computadores mais rápidos. }\end{array}$ & $\begin{array}{l}\text { Recodificado para } \\
\text { processo }\end{array}$ \\
\hline Processo & $\begin{array}{l}\text { É um processo contínuo de melhoria nos } \\
\text { processos de fabricação }\end{array}$ & $\begin{array}{l}\text { Recodificado para } \\
\text { não realização } \\
\text { de inovação } \\
\text { tecnológica }\end{array}$ \\
\hline Processo & $\begin{array}{l}\text { Implantação de sistema de informatização } \\
\text { administrativa e financeira }\end{array}$ & $\begin{array}{l}\text { Recodificado para } \\
\text { não realização } \\
\text { de inovação } \\
\text { tecnológica }\end{array}$ \\
\hline Processo & $\begin{array}{l}\text { Inovação do processo com a botoeira } \\
\text { inteligente - antes bipava (fazia barulho), } \\
\text { agora fala [...] adequado para pessoas } \\
\text { com problema grave de visão [...] fica na } \\
\text { coluna do semáforo, manda mensagem }\end{array}$ & $\begin{array}{l}\text { Recodificado para } \\
\text { produto }\end{array}$ \\
\hline
\end{tabular}

Fonte: Pesquisa de Diagnóstico da Oferta e da Demanda de Serviços Tecnológicos das Empresas do Setor Metal-Mecânico do Grande ABC. 
TABELA 1

Distribuição das ocorrências relativas às descrições apresentadas na questão de expansão do levantamento sobre realização de inovação em unidades do setor metal-mecânico

Região do Grande ABC - 2009

\begin{tabular}{l|c|c|c|c|}
\hline \hline $\begin{array}{c}\text { Tipo de } \\
\text { inovação }\end{array}$ & $\begin{array}{c}\text { Total de casos } \\
\text { (descrições } \\
\text { apresentadas } \\
\text { na questão de } \\
\text { expansão) }\end{array}$ & $\begin{array}{c}\text { Descrição } \\
\text { pertinente ao } \\
\text { processo de } \\
\text { inovação afir- } \\
\text { mado pelo } \\
\text { entrevistado }\end{array}$ & $\begin{array}{c}\text { Descrição } \\
\text { não perti- } \\
\text { nente à } \\
\text { inovação } \\
\text { tecnológica }\end{array}$ & $\begin{array}{c}\text { Descrição perti- } \\
\text { nente à inovação } \\
\text { tecnológica, mas } \\
\text { com compreensão } \\
\text { equivocada quanto } \\
\text { à modalidade de } \\
\text { inovação ocorrida }\end{array}$ \\
\hline $\begin{array}{l}\text { Inovação em } \\
\text { produto } \\
\text { Inovação em } \\
\text { processo } \\
\text { Total }\end{array}$ & 161 & 127 & 26 & $\begin{array}{c}\text { (transferidas para } \\
\text { processo) }\end{array}$ \\
\hline \hline
\end{tabular}

Fonte: Pesquisa de Diagnóstico da Oferta e da Demanda de Serviços Tecnológicos das Empresas do Setor Metal-Mecânico do Grande ABC.

Considerando-se que a amostra foi probabilística no âmbito do setor metal-mecânico da Região do Grande $\mathrm{ABC}$, investigou-se sobre a diferença de proporção de descriçôes não pertinentes entre os levantamentos sobre inovação em produto e em processo. Para isso, foi utilizado o teste qui-quadrado para diferença de duas proporções (SIEGEL, 1975).

TABELA 2

Síntese de acertos (descrições pertinentes à modalidade informada) e erros (descrições não pertinentes à modalidade informada) relativos às inovações em produto e em processo em unidades do setor metal-mecânico Região do Grande ABC - 2009

\begin{tabular}{|c|c|c|c|c|c|c|}
\hline \multirow{3}{*}{ Tipo de inovação } & \multicolumn{4}{|c|}{ Classificação da descrição } & \multirow{2}{*}{\multicolumn{2}{|c|}{ Total }} \\
\hline & \multicolumn{2}{|c|}{ Certa } & \multicolumn{2}{|c|}{ Errada } & & \\
\hline & N. abs. & $\%$ & N. abs. & $\%$ & N. abs. & $\%$ \\
\hline $\begin{array}{l}\text { Descrição da inovação em } \\
\text { produto }\end{array}$ & 127 & 78,9 & 34 & 21,1 & 161 & 48,1 \\
\hline $\begin{array}{l}\text { Descrição da inovação em } \\
\text { processo }\end{array}$ & 153 & 87,9 & 21 & 12,1 & 174 & 51,9 \\
\hline Total & 280 & 83,6 & 55 & 16,4 & 335 & 100,0 \\
\hline Estatística qui-quadrado (1) & & & 43 & $(p<c$ & & \\
\hline
\end{tabular}

Fonte: Pesquisa de Diagnóstico da Oferta e da Demanda de Serviços Tecnológicos das Empresas do Setor Metal-Mecânico do Grande ABC.

(1) Hipótese nula: A proporção de declaraçâes não pertinentes sobre inovação em produto é igual à proporção de declaraçōes não pertinentes em processo. 
O valor calculado da estatística $\chi^{2}$ equivaleu a 43,524. A tomada de decisão é, portanto, em favor da rejeição da hipótese nula para um nível de significância inferior a 5\%, implicando a existência de diferença entre a proporção de descrições certas para produtos e descriçóes certas para processo.

De acordo com os dados amostrais, a proporção de descrições não pertinentes em inovação de produto equivaleu a $21,1 \%$ dos casos declarados como inovação em produto contra $12,0 \%$ de descrições não pertinentes dos casos declarados de inovação em processo, sugerindo maior imprecisão da estimativa das inovaçôes em produto. De forma agregada, 19,6\% das descrições de inovações em produto e em processo apresentaram não pertinência.

Nesse sentido, a Tabela 3 apresenta a proporção de empresas que realizaram inovação declarada e a proporção tratada pelo procedimento de correção. Registre-se que o intervalo de confiança para a verdadeira proporção de realização de inovação em produto, inovação em processo e total não contém a estimativa pontual declarada (não corrigida), corroborando os achados de que a ocorrência desse tipo de erro de mensuração devido à compreensão imprecisa do conceito implícito na pergunta é estatisticamente significante.

TABELA 3

Proporção de empresas do setor metal-mecânico que realizam inovação: declarado $x$ corrigido Região do Grande ABC - 2009

\begin{tabular}{|c|c|c|c|}
\hline & & & Em porcentagem \\
\hline Tipo de inovação & $\begin{array}{c}\text { Proporção } \\
\text { estimada a partir } \\
\text { da declaração dos } \\
\text { entrevistados }\end{array}$ & $\begin{array}{l}\text { Proporção } \\
\text { corrigida }\end{array}$ & $\begin{array}{c}\text { Intervalo de } \\
\text { confiança para } \\
\text { verdadeira } \\
\text { proporção ( } 95 \% \\
\text { de confiança) }\end{array}$ \\
\hline Inovação em produto & 32,2 & 25,4 & {$[21,6 ; 29,2]$} \\
\hline Inovação em processo & 34,8 & 30,6 & {$[26,6 ; 34 ., 6]$} \\
\hline $\begin{array}{l}\text { Total (processo e/ou } \\
\text { produto) }\end{array}$ & 67,0 & 56,0 & {$[51,7 ; 60,4]$} \\
\hline
\end{tabular}

Fonte: Pesquisa de Diagnóstico da Oferta e da Demanda de Serviços Tecnológicos das Empresas do Setor Metal-Mecânico do Grande ABC.

\section{Conclusão}

A formalização dos procedimentos para detecção e correção do erro não amostral, decorrente da coleta do dado numa situação de compreensão imprecisa do con- 
ceito implícito na questão por parte do entrevistado, confere papel fundamental à presença de questão aberta, na condição de questão de expansão sobre as características da inovação em produto e/ou em processo. Isso porque a questão aberta, de um lado, possibilita evidenciar a presença da compreensão equivocada por parte dos respondentes sobre o conceito de inovação tecnológica, mesmo quando esse conceito é informado durante o processo de coleta de dados, e, de outro, permite obter uma evidência da ocorrência de viés de mensuração da inovação em produto e em processo quando a coleta limita-se à questão fechada do tipo dicotômica para apurar a realização desses tipos de inovação.

Em particular, nesse estudo, a presença da pergunta de expansão no instrumento de coleta de dados da pesquisa sobre inovação tecnológica contribuiu também para a precisão do resultado final dos estudos, considerando a possibilidade de ajuste da resposta apresentada pela unidade respondente

Sobre a compreensão equivocada, registre-se que a verificação de maior proporção de viés entre os casos de inovação em produto pode sugerir que esse conceito de inovação implícito no levantamento seria mais complexo para o gestor das micro e pequenas empresas do que o conceito implícito de inovação em processo. Nesse contexto, evidencia-se um espaço para novos estudos que aprofundem essa questão e que possam evidenciar mecanismos indutores de maior assimilação do conceito, o que contribuiria para reduzir a parcela do erro total de levantamento proveniente da componente não amostral.

A estimativa do indicador de empresas inovadoras na amostra do setor metal-mecânico, sem a aplicação dos procedimentos de detecção e correção do viés da informação, confirma a superestimação desse indicador no âmbito das inovações tanto em produto como em processo. A significância estatística encontrada para a diferença entre essa estimativa e a obtida após a aplicação dos procedimentos de detecção e correção do dado originalmente informado sustenta a afirmação.

Assim, essa situação corrobora a ocorrência de viés de mensuração em algum grau nos levantamentos sobre inovação, caso o seu desenho não tenha considerado a multiplicidade de fontes de erro não amostral e não tenha delineado procedimentos eficazes para sua minimização.

Particularmente no ambiente das micro e pequenas empresas, a questão de expansão torna muito mais aparente o espaço dentro do qual a questão da inovação tecnológica é entendida pelo respondente, revelando, por vezes, o distanciamento entre aquilo que o conceito invoca e o que o respondente compreende, conforme evidenciado na análise dos conteúdos. 
Maria do Carmo Romeiro, Leandro Campi Prearo, Marco Antonio Pinheiro da Silveira, João de Paula Ribeiro Neto

\section{Referências bibliográficas}

ADVISORY COMMITTEE ON MEASURING INNOVATION IN THE 21ST CENTURY ECONOMY, THE. Innovation measurement: Tracking the state of innovation in the American economy. Washington: US Department of Commerce, 2008

AGÊNCIA DE DESENVOLVIMENTO ECONÔMICO DO GRANDE ABC. Pesquisa Diagnóstico da Oferta e Demanda de Serviços Tecnológicos das Empresas do Setor Metal-Mecânico do Grande ABC. São Caetano do Sul: Inpes - USCS, 2009.

ARUNDEL, A. Innovation survey indicators: what impact on innovation policy? Science, technology and innovation indicators an a changing world: responding to policy needs. OECD, 2007.

BACHMANN, D. L.; DESTEFANI, J. H. Metodologia para estimar o grau de inovação nas MPE. In: XVIII Seminário Nacional de Parques Tecnológicos e Incubadoras de Empresas. Anais... 2008.

BERNDT, A.; OLIVEIRA, L. H. A construção do saber administrativo por meio de replicagens em pesquisas por levantamento (survey). Revista ANGRAD, v. 6, n. 3, p.9-26, jul.-ago.-set. 2005.

BIEMER, P. P. total survey error - design, implementation, and evaluation. Public Opinion Quarterly, v. 74,n. 5, p. 817-848, 2010.

BLINDENBACH-DRIESSEN, F.; DALEN, J. van; ENDE, J. van den. Subjective performance assessment of innovation projects. Product Development \& Management Association, v. 27, p. 572-592, 2010.

COMITE DE TECNOLOGIA E INOVAÇĀO. Desenvolvimento tecnológico e inovação nas microempresas e empresas de pequeno porte: fatores de influência. Fórum Permanente das Microempresas e Empresas de Pequeno Porte. Brasília: Ministério do Desenvolvimento, Indústria e Comércio Exterior, 2007.

COOPER, D. R.; SCHINDLER, P. S. Métodos de pesquisa em administração. $7^{\text {a }}$ ed. Porto Alegre: Bookman, 2003.

GODOY, R. S. P. Relações entre cultura organizacional e processos de inovação em empresas de base tecnológica. Dissertação (Mestrado em Engenharia de Produção) - Escola de Engenharia de São Carlos (EESC), São Carlos, 2009.

HAIR JR., J. F. et al. Fundamentos de métodos de pesquisa em administração. Porto Alegre: Bookman, 2005.

HEGEDUS, C. E. N. A introdução de novos produtos e o processo de difusão das inovações na estratégia das empresas: uma análise de bens duráveis. Tese (Doutorado em Engenharia de Produção) - Escola Politécnica da USP, São Paulo, 2006. 
IBGE. Pesquisa Industrial de Inovação Tecnológica 2008. Rio de Janeiro, 2010.

INÁCIO JR., E. Padrōes de inovação em pequenas e médias empresas e suas implicações para o desempenho inovativo e organizacional. Tese (Doutorado em Política Científica e Tecnológica) - Instituto de Geociências da Unicamp, Campinas, 2008.

JARAMILlO, H.; LUGONES, G.; SALAZAR, M. Manual de Bogotá - Normalización de indicadores de innovación tecnológica en América Latina. Bogotá: Colciencias, Ricyt, Cyted, OEA, 2001.

KLINK, R. R.; ATHAIDE G. A. An illustration of potential sources of concept-test error. Product Development \& Management Association, v. 3, p. 359-370, 2006.

KUPFER, D.; ROCHA, F. Determinantes setoriais do desempenho das empresas industriais brasileiras. In: DE NEGRI, J. A.; SALERNO, M. S. (Orgs.). Inovaçōes, padrões tecnológicos e desempenho das firmas industriais brasileiras. Brasília: Ipea, 2005.

LEES, G.; WRIGHT, M. The effect of concept formulation on concept test scores. Product Development \& Management Assossiation, v. 21, p. 389-400, 2004.

OLIVEIRA, A. C. Diretrizes de apoio ao esforço de inovação tecnológica no desenvolvimento de produtos em pequenas e médias empresas industriais. Tese (Doutorado em Engenharia Mecânica) - Escola Politécnica da USP, São Paulo, 2007.

O'CATHAIN, A.; THOMAS, K. J. “Any other comments?” Open questions on questionnaires: a bane or a bonus to research? BMC Medical Research Methodology, v. 4, p. 25-27, Jan. 2004.

OCDE. Proposta de práticas exemplares para inquéritos sobre investigação e desenvolvimento experimental - Manual de Frascati. OCDE, F. Iniciativas, 2007.

Diretrizes para coleta e interpretação de dados sobre inovação - Manual de Oslo.

$3^{\mathrm{a}}$ ed. OCDE, Eurostat, Finep, 2005

. Manual of the measurement of human resources devoted to Science and Technology

- Canberra Manual. Bruxelas: OCDE, 1995.

PACAGNELLA JR., A. C. A inovação tecnológica nas indústrias do Estado de São Paulo: uma análise dos indicadores da PAEP. Dissertação (Mestrado em Administração de Organizações) - Faculdade de Economia, Administração e Contabilidade de Ribeirão Preto (Fearp), Ribeirão Preto, 2006.

PRADO, F. L. Uma análise métrica das principais tipologias de inovação. Dissertação (Mestrado em Administração de Empresas) - Pontifícia Universidade Católica de São Paulo, São Paulo, 2009.

QUADROS, R. et al. Technological innovation in Brazilian industry: an assessment based on the São Paulo innovation survey. Technological Forecasting and Social Change, v. 67, p. 203-219, 2002. 
Maria do Carmo Romeiro, Leandro Campi Prearo, Marco Antonio Pinheiro da Silveira, João de Paula Ribeiro Neto

SAKSHAUG, J. W.; YAN, T.; TOURANGEAU, R. Nonresponse error, measurement error, and mode of data collection - Tradeoffs in a multi-mode survey of Sensitive and non-sensitive items. Public Opinion Quarterly, v. 74, n. 5, p. 907-933, 2010.

SAWHNEY, M. et al. The 12 different ways for companies to innovate. MIT Sloan Management Review, spring 2006.

SEBRAE. Diretrizes para atuação do sistema SEBRAE em acesso à inovação e tecnologia. Brasília: Sebrae, 2007.

SIEGEL, S. Estatística não-paramétrica para as ciências do comportamento. São Paulo: Makron Books do Brasil, 1975.

SMITH, T. W. Refining the total survey error perspective. International Journal of Public Opinion Research, v. 23, p. 464-484, 2011.

TOURANGEAU, R. Cognitive aspects of survey - Measurement and mismeasurement. International Journal of Public Opinion Research, v. 15, n. 1, p. 3-7, 2003.

VILHENA, F. PINTEC 2008 - Informaçôes preliminares. 2010 (slides). Disponível em: <http://www.redetec.org.br/redeseprogramas/redestematicas/repict/pdf/xiiiRepictFernanda2dia.pdf>. Acesso em 15 set. 2010.

WALKER, R. An empirical evaluation of innovation types and organizational and environmental characteristics: towards a configuration framework. Journal of Public Administration Research and Theory, v. 18, n. 4, p. 591-615, 2008.

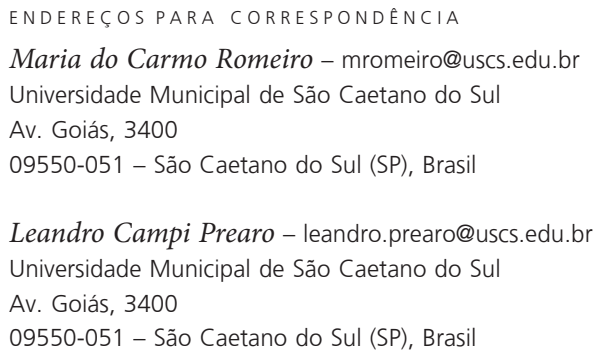

